\title{
Tests on Cementless Alkali-Activated Slag Concrete Using Lightweight Aggregates
}

\author{
Keun-Hyeok Yang, ${ }^{1), *}$ Ju-Hyun Mun, ${ }^{2)}$ Kang-Seok Lee, ${ }^{3)}$ and Jin-Kyu Song ${ }^{3)}$
}

(Received June 7 2011, Revised September 30, 2011, Accepted October 25, 2011)

\begin{abstract}
Five all-lightweight alkali-activated (AA) slag concrete mixes were tested according to the variation of water content to examine the significance and limitation on the development of cementless structural concrete using lightweight aggregates. The compressive strength development rate and shrinkage strain measured from the concrete specimens were compared with empirical models proposed by ACI 209 and EC 2 for portland cement normal weight concrete. Splitting tensile strength, and moduli of elasticity and rupture were recorded and compared with design equations specified in ACI 318-08 or EC 2, and a database compiled from the present study for ordinary portland cement (OPC) lightweight concrete, wherever possible. Test results showed that the slump loss of lightweight AA slag concrete decreased with the increase of water content. In addition, the compressive strength development and different mechanical properties of lightweight AA slag concrete were comparable with those of OPC lightweight concrete and conservative comparing with predictions obtained from code provisions. Therefore, it can be proposed that the lightweight AA slag concrete is practically applicable as an environmental-friendly structural concrete.
\end{abstract}

Keywords: alkali-activated concrete, slag, lightweight aggregates, workability, mechanical properties, shrinkage strain.

\section{Introduction}

A large portion of the concrete industry has growing interest in minimizing the use of ordinary Portland cement (OPC), because it is generally estimated that the amount of greenhouse gas (GHS) emitted from the worldwide production of OPC corresponds to approximately $7 \%$ of the total GHS emissions into the Earth's atmosphere ${ }^{1-3}$. As a result, various investigations ${ }^{4-6}$ have been conducted in several fields to develop a cementless alkali-activated (AA) ground granulated blast-furnace slag binder together with a fly ash-based geopolymer binder. It is also generally estimated that the amount of carbon dioxide $\left(\mathrm{CO}_{2}\right)$ emitted from the consumption of fossil fuels for commercial and residential heating accounts for approximately $12 \%$ of the total $\mathrm{CO}_{2}$ emissions into the earth's atmosphere. In addition, the non-negligible amounts of $\mathrm{CO}_{2}$ are emitted from buildings and/or factory cooling ${ }^{7}$. As a result, the development of energy saving systems and new and renewable energy sources has become one of the hottest issues in building structures. The use of lightweight concrete as a building material is highly effective for saving energy due to the enhanced

\footnotetext{
${ }^{1)}$ KCI Member, Kyonggi University, Dept. of Architectural. Eng., Suwon 443-760, Korea. *Corresponding Author; E-mail: yangkh @kyonggi.ac.kr

${ }^{2)}$ KCI Member, Mokpo National University, Dept. of Architectural. Eng., Muan 534-729, Korea.

${ }^{3}$ KCI Member, Chonnam National University, Dept. of Architectural. Eng., Gwangju 500-757, Korea.

Copyright (c) 2011, Korea Concrete Institute. All rights reserved, including the making of copies without the written permission of the copyright proprietors.
}

thermal insulation capacity through the lower thermal conductivity of lightweight aggregates. ${ }^{7-9}$ In addition, the application of lightweight concrete as a building material has several advantages in structural and environmental terms, as pointed out by Kayali. ${ }^{10}$

Synergy effects are expected when AA slag binder and lightweight aggregates are combined to produce environmentallyfriendly concrete because of the various advantages of both materials. One of the most significant effects is the highly reduced $\mathrm{CO}_{2}$ emission from concrete building structures by the use of AA slag binder with a lower $\mathrm{CO}_{2}$ emission and an energy saving effect owing to the use of lightweight aggregates. In addition, precast concrete can be produced with good quality and economical efficiency from an early higher-strength development capacity of AA slag paste and a lower density of aggregates. However, the available experimental data ${ }^{11,12}$ needed to determine a reliable mixing design and the mechanical properties of lightweight AA slag concrete are very rare.

In the present study, five all-lightweight AA slag concrete mixes were tested in order to evaluate the effect of the water content on the workability, mechanical properties, and shrinkage strain of the concrete. The rate of compressive strength development and the shrinkage strain were measured and compared with the empirical models proposed by ACI $209^{13}$ for normal-weight portland cement concrete. To examine the practical applicability of the lightweight AA slag concrete, the splitting tensile strength and the moduli of elasticity and rupture recorded from the concrete specimens were compared with the values predicted through various sources for lightweight OPC concrete, whenever possible. These sources included design equations specified in ACI 318-08 ${ }^{14}$ or EC $2^{15}$, empirical equations proposed by Slate et al. ${ }^{16}$, and a data- 
base compiled by Sim et al. ${ }^{17}$.

\section{Experimental details}

\subsection{Materials}

Ground granulated blast-furnace slag (GGBS) was activated by sodium silicate $\left(\mathrm{Na}_{2} \mathrm{O} \cdot \mathrm{SiO}_{2}\right)$ and calcium hydroxide $\left(\mathrm{Ca}(\mathrm{OH})_{2}\right)$ powders and used as a cementitious binder. Alkali hydroxide (ROH), non-silicic salts of weak acids $\left(\mathrm{R}_{2} \mathrm{CO}_{3}, \mathrm{R}_{2} \mathrm{~S}, \mathrm{RF}\right)$, and/or silicic salts of $\mathrm{R}_{2} \mathrm{O} \cdot(\mathrm{n}) \mathrm{SiO}_{2}$ type are used as effective activators, where $\mathrm{R}$ indicates an alkali metal ion such as $\mathrm{Na}, \mathrm{K}$ or $\mathrm{Li}$, because the reaction of a solid aluminosilicate with a highly concentrated aqueous alkali hydroxide or silicate solution can produce a synthetic alkali aluminosilicate material. However, it has also been pointed out ${ }^{6}$ that several practical problems are associated with pastes that are activated by alkali solutions, including over-rapid setting, the risk of handling the material outside the laboratory environment, and the occurrence of efflorescence. In addition, AA pastes activated by sodium silicate or potassium silicate show a reduced strength and poor durability in water environments, because hydration products have a number of dissolution characteristics in water. ${ }^{5}$ In particular, $\mathrm{Na}_{2} \mathrm{O}$ involving $\mathrm{K}_{2} \mathrm{O}$ content in cementitious materials should be below $0.8 \%$ in order to control the possibility of an alkali-aggregate reaction. For practical application of alkali-activated (AA) GGBS concrete, the present study selected $\mathrm{Ca}(\mathrm{OH})_{2}$ as a main activator due to its low cost and good durability. ${ }^{18}$ The $\mathrm{Ca}(\mathrm{OH})_{2}$-activated GGBS binder generally has an advantage in regard to a relatively relieved workability loss, while intermittently shows an unsoundness due to lime depending on to the curing condition and the dosage of $\mathrm{Ca}(\mathrm{OH})_{2} .{ }^{18}$

The GGBS used for the source material had a high $\mathrm{CaO}$ content and $\mathrm{SiO}_{2}-$ to- $\mathrm{Al}_{2} \mathrm{O}_{3}$ ratio by mass of 2.29 , as given in Table 1 . The specific gravity and specific surface area measured from the GGBS were 2.2 and $4,200 \mathrm{~cm}^{2} / \mathrm{g}$, respectively. The sodium silicate powder used was a compound of $50.2 \%$ sodium oxide $\left(\mathrm{Na}_{2} \mathrm{O}\right)$ and $45 \%$ silicon oxide $\left(\mathrm{SiO}_{2}\right)$, producing a molar ratio $\left(\mathrm{SiO}_{2} / \mathrm{Na}_{2} \mathrm{O}\right)$ of 0.9 . The purity of the $\mathrm{Ca}(\mathrm{OH})_{2}$ powder used was 95.8\%.

Yang et al. ${ }^{18}$ also recommended that the ratios by weight of $\mathrm{Ca}(\mathrm{OH})_{2}$ to the binder including the GGBS and alkali activators, and of $\mathrm{Na}_{2} \mathrm{O}$ in sodium silicate to GGBS were above $7.5 \%$ and

Table 1 Chemical composition of GGBS used.

\begin{tabular}{c|c|c|c|c|c|c|c|c|c}
\hline $\mathrm{SiO}_{2}$ & $\mathrm{Al}_{2} \mathrm{O}_{3}$ & $\mathrm{Fe}_{2} \mathrm{O}_{3}$ & $\mathrm{CaO}$ & $\mathrm{MgO}$ & $\mathrm{K}_{2} \mathrm{O}$ & $\mathrm{Na}_{2} \mathrm{O}$ & $\mathrm{TiO}_{2}$ & $\mathrm{SO}_{3}$ & LOI* $^{*}$ \\
\hline \hline 31.55 & 13.79 & 0.53 & 44.38 & 5.2 & 0.4 & 0.18 & 0.98 & 2.79 & 0.2 \\
\hline
\end{tabular}

* Loss on ignition.

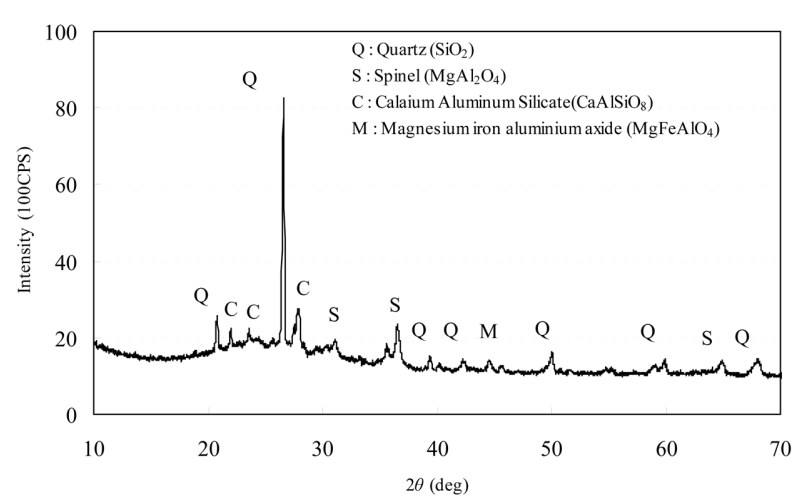

Fig. 1 XRD patterns of lightweight aggregates used.

$3 \%$, respectively, to facilitate the chemical reaction by ion exchange between the silicate anions of the GGBS and the cations of the alkaline activators. Therefore, the $\mathrm{Ca}(\mathrm{OH})_{2}$-to-binder ratio was selected to be $7.5 \%$ and sodium silicate was added so that the $\mathrm{Na}_{2} \mathrm{O}$-to-GGBS ratio would be $3 \%$ in order to produce a cementless alkali-activated slag binder.

Artificially expanded clay granules with maximum sizes of $19 \mathrm{~mm}$ and $5 \mathrm{~mm}$ were used for lightweight coarse and fine aggregates, respectively. From X-ray diffraction measurements shown in Fig. 1, the main composition of the lightweight aggregates was quartz and calcium aluminum silicate. Fig. 2 shows that the lightweight aggregates were spherical in the shape and had a closed surface with a slightly rough texture. The core of the particle had a uniformly fine and porous structure, which led to high thermal and acoustic insulation but induced high water absorption and low strength. In particular, the rate of water absorption of lightweight aggregates was extremely fast for the lightweight

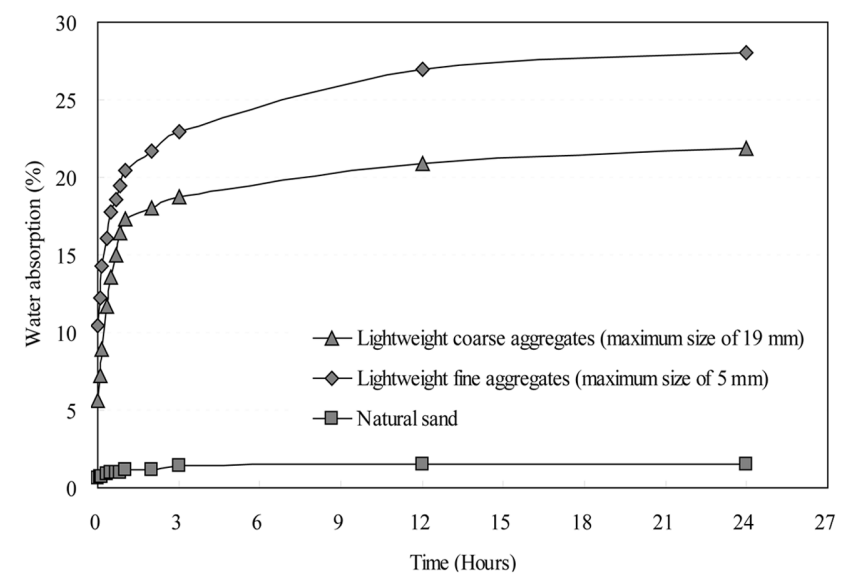

Fig. 3 Water absorption rates of the aggregates used.

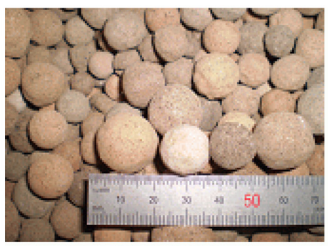

Typical shape

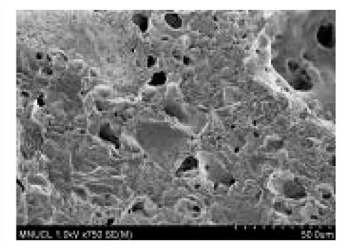

Internal micro-structures $(\times 750)$

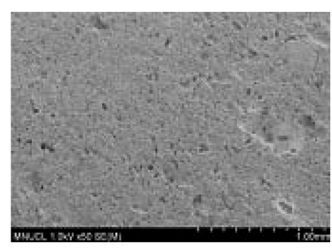

Internal micro-structures

$(\times 50)$

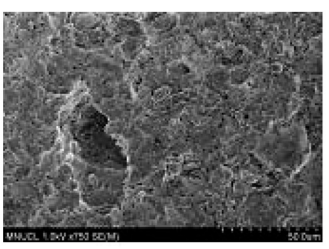

External surface $(\times 750)$

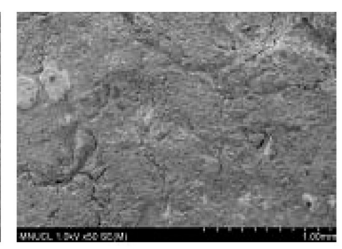

External surface $(\times 50)$

Fig. 2 Shape and scanning electron microscope (SEM) images of the lightweight coarse aggregate used. 
Table 2 Properties of the lightweight aggregates used.

\begin{tabular}{c|c|c|c|c}
\hline Maximum size $[\mathrm{mm}]$ & Specific gravity & Water absorption $[\%]$ & Fineness modulus & Unit volume weight $\left(\mathrm{kg} / \mathrm{m}^{3}\right)$ \\
\hline \hline 19 & 1.04 & 21.95 & 6.68 & 729 \\
\hline 5 & 1.65 & 28.0 & 2.43 & 800 \\
\hline
\end{tabular}

aggregates during the first three hours and then the absorption rate slowed down, as shown in Fig. 3. The physical properties of the aggregates used are shown in Table 2 . The specific gravity of the lightweight aggregates used was low, whereas water absorption of that was very high.

\subsection{Mix proportions}

Five all-lightweight AA slag concrete mixes were prepared by varying the water content per unit volume of concrete, as given in Table 3. The compressive strength of lightweight AA slag concrete targeted in the present study was above $24 \mathrm{MPa}$ for application to structural concrete members. From various preliminary tests, the water-binder ratio by weight and fine aggregate-to-total aggregate ratio by volume were fixed at $30 \%$ and $40 \%$, respectively, in all concrete mixes. The mixture proportions of all the concrete specimens were determined based on the weight method proposed by ACI $211^{19}$.

\subsection{Casting, curing, and testing}

Lightweight aggregates were dampened for 24 hours and then air-dried for another 24 hours to simulate the saturated surface dried-state which is commonly employed in ready-mixed concrete plants. The alkaline binder and aggregates were dry-mixed in a pan mixer for 1 minute. Then water was added and mixed for another 1 minute. For all the concrete mixes, a polycarbonatebased water-reducing admixture with an air entraining agent was added by $0.5 \%$ relative to the amount of binder used. After the initial slump was tested, each mix was poured into various steel moulds to measure the compressive strengths and other mechanical properties. Immediately after casting, all specimens were cured at a constant temperature and relative humidity of $21 \pm 2^{\circ} \mathrm{C}$ and 60 $\pm 2 \%$, respectively.

For fresh concrete, the initial slump was recorded immediately after mixing and the variation of slump was measured at 30,60,

Table 3 Details of lightweight AA slag concrete mixes

\begin{tabular}{|c|c|c|c|c|c|c|c|}
\hline \multirow{3}{*}{ Specimen } & \multirow{3}{*}{$W / B$} & \multicolumn{6}{|c|}{ Unit weight $\left[\mathrm{kg} / \mathrm{m}^{3}\right]$} \\
\hline & & \multirow{2}{*}{$W$} & \multicolumn{3}{|c|}{$B$} & \multirow{2}{*}{$S_{L W}$} & \multirow{2}{*}{$G_{L W}$} \\
\hline & & & GGBS & $\mathrm{Ca}(\mathrm{OH})_{2}$ & $\mathrm{Na}_{2} \mathrm{SiO}_{3}$ & & \\
\hline $\mathrm{W} 150$ & \multirow{5}{*}{0.3} & 150 & 413 & 38 & 49 & 421 & 398 \\
\hline W165 & & 165 & 454 & 41 & 54 & 399 & 378 \\
\hline W180 & & 180 & 496 & 45 & 59 & 377 & 357 \\
\hline W195 & & 195 & 537 & 59 & 64 & 356 & 336 \\
\hline W210 & & 210 & 578 & 53 & 69 & 338 & 315 \\
\hline
\end{tabular}

Note : $W, B, S_{L W}$ and $G_{L W}$ refer to water, binder organized by the GGBS and alkali activators, lightweight aggregate with a maximum size of $5 \mathrm{~mm}$, and lightweight coarse aggregate with a maximum size of $19 \mathrm{~mm}$, respectively.

In all concrete mixes, a polycarbonate-based water-reducing admixture with an air-entraining agent was added by $0.5 \%$ relative to the amount of binder.
90 and 120 minutes after mixing. On the other hand, the compressive strength, splitting tensile strength, moduli of elasticity and rupture, and unrestrained shrinkage strain were measured for the hardened concrete. The compressive strength of the concrete specimens was tested using $100 \times 200 \mathrm{~mm}$ cylinders at ages of $1,3,7$, 28, 56 and 91 days to investigate the strength gain over time, while the other mechanical properties were only recorded at an age of 28 days. The modulus of elasticity of concrete specimens was determined from the slope between a zero stress and $45 \%$ stress of the compressive strength ${ }^{14}$. The testing procedures for the above experiments were conducted in accordance with the KS specifications ${ }^{20}$ for testing OPC concrete. The unrestrained shrinkage strains of different concrete specimens were monitored by using $100 \mathrm{~mm}$ waterproof electrical resistance strain (ERS) gages attached longitudinally at the centers of the $150 \times 150 \times 450 \mathrm{~mm}$ steel moulds before the concrete was cast. All the shrinkage strain readings after de-molding at age one day were recorded and saved automatically using a data logger for the first 50 days.

\section{Test results and discussions}

\subsection{Initial slump and slump loss}

The initial slump of the lightweight AA slag concrete increased with the increase of water content, which is generally observed in the lightweight OPC concrete as well ${ }^{8,9}$. The relatively round and smooth surface texture of the lightweight aggregates led to the improved initial workability of concrete. On the other hand, the slump, $S$, of the concrete tested sharply decreased over the elapsed time, as shown in Fig. 4. The high rate of water absorption of lightweight aggregates as shown in Fig. 3 and the rapid reaction of sodium silicate resulted in the quick setting of concrete, showing that no slump could be measured after 60 minutes in all-lightweight concrete mixes with a water content under $165 \mathrm{~kg} / \mathrm{m}^{3}$. However, the increase of water content alleviated the slump loss of the concrete specimens. This maybe attributed to the fact that the increased water content results in a decrease in the volume of

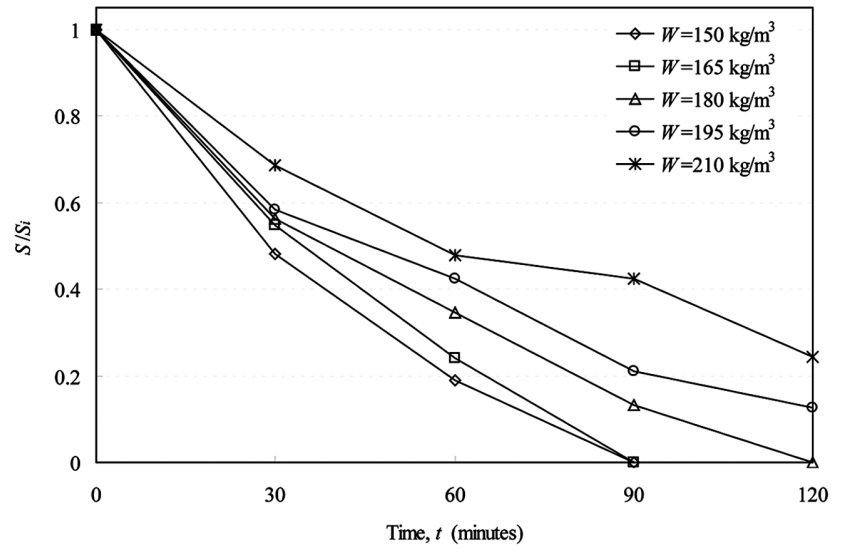

Fig. 4 Relative slump against the elapsed time. 
lightweight aggregates mixed in the concrete and an increase of the free water between hydrated gels.

\subsection{Compressive strength at 28 days and strength development}

The 28-day compressive strength, $f_{c}^{\prime}$, of lightweight AA slag concrete slightly increased with the increase of the water content, as listed in Table 4. The failure planes of lightweight concrete generally pass through the lightweight aggregates and the number of interfacial cracks between lightweight aggregates and pastes increases with the increase of the amount of lightweight aggregates ${ }^{12}$. As a result, the reduced volume of lightweight aggregates mixed in the concrete due to the increased water content can lead to a slightly higher compressive strength of concrete. On the other hand, the compressive strength of lightweight concrete increased with the increase of its dry density, showing a similar increasing rate in both lightweight AA slag and OPC concretes, as presented in Fig. 5. At the same dry density, a higher strength was observed in lightweight AA slag concrete than in lightweight OPC concrete. It is generally known ${ }^{6}$ that the sodium-containing hydrated gels formed in AA slag pastes have low crystallinity and tighter intensities than those generally observed in OPC pastes. This more elaborated gel product reduces interfacial cracks between lightweight aggregates and pastes, which can lead to an increase of compressive strength of concrete.

In general, the development of the compressive strength of OPC concrete is simulated as a parabolic function, as the increasing rate of compressive strength development decreases with the increase of age. The ACI $209^{13}$ proposed the compressive strength development of cement concrete with age in the following form:

$$
f_{c}^{\prime}(t)=\frac{t}{A_{1}+B_{1}} f_{c}^{\prime}
$$

where, $f_{c}{ }^{\prime}(t)$ is the compressive strength at age $t$ (in days). The constants $A_{1}$ and $B_{1}$ in Eq. 1 generally relate to the development of strength at an early age and a long-term age, respectively. In particular, lower values of $A_{1}$ and $B_{1}$ indicate higher rates of compressive strength development at the early and long-term ages, respectively. The compressive strength development of concrete tested occurred in a parabolic shape, as shown in Fig. 6. From the test results given in Table 4, the constants $A_{1}$ and $B_{1}$ in Eq. 1 were determined from non-linear regression analysis using the SPSS software, whereby a correlation coefficient above 0.96 was obtained for all the concrete specimens.

The constants $A_{1}$ and $B_{1}$ determined from the concrete tested are plotted in Fig. 7. In the same figure, both constants specified in

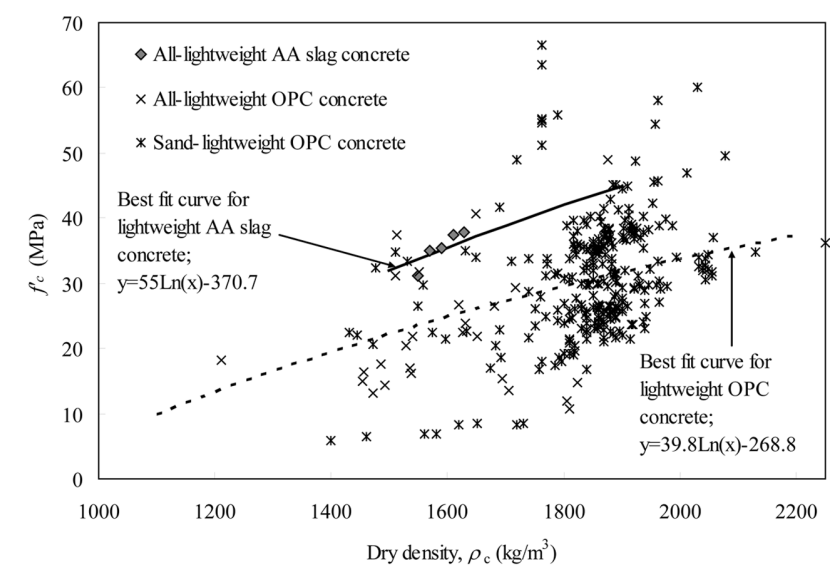

Fig. 5 Dry density versus 28-day compressive strength.

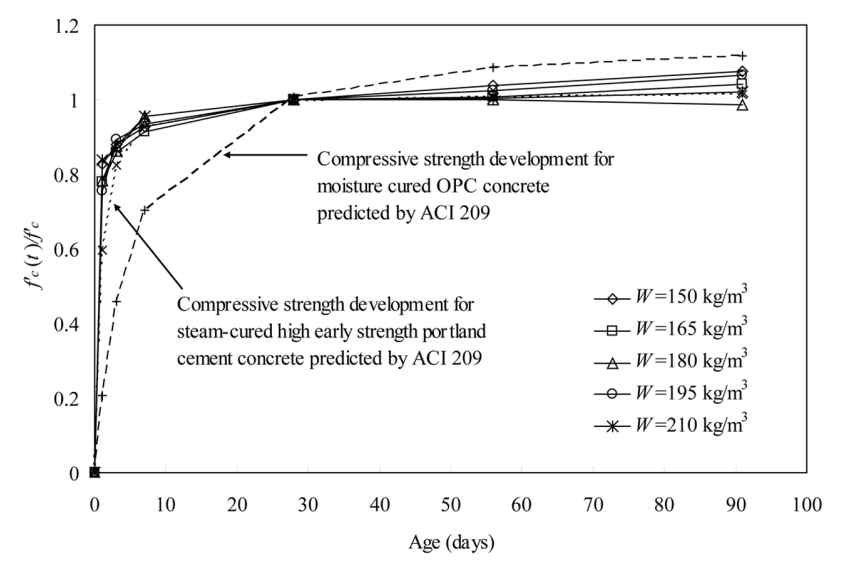

Fig. 6 Typical compressive strength development of all-lightweight AA slag concrete.

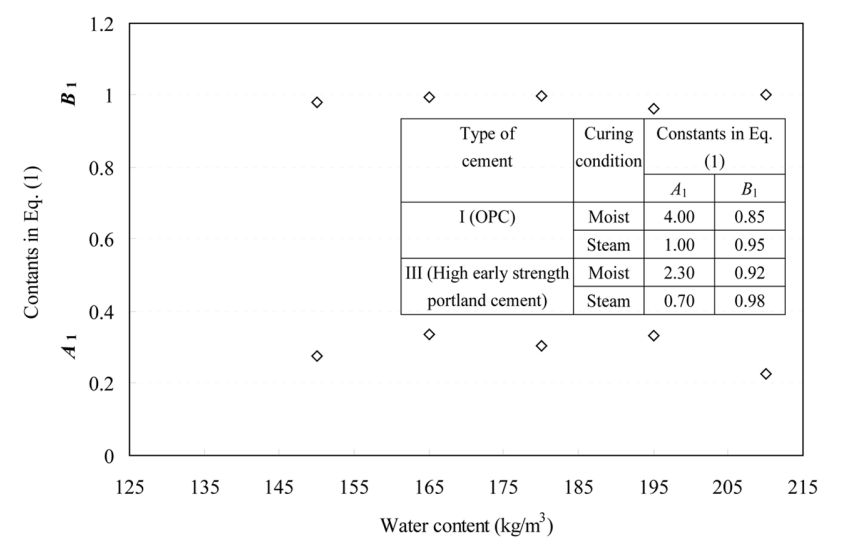

Fig. 7 Comparisons of both constants in Eq. 1 determined from concrete specimens and specified in $\mathrm{ACl} 209$.

Table 4 Summary of the workability and compressive strength.

\begin{tabular}{|c|c|c|c|c|c|c|c|c|c|c|c|c|}
\hline \multirow{2}{*}{ Specimen } & \multirow{2}{*}{$\begin{array}{c}\text { Dry density } \\
\rho_{c}\left[\mathrm{~kg} / \mathrm{m}^{3}\right]\end{array}$} & \multicolumn{5}{|c|}{ Slump [mm] against elapsed time [minutes] } & \multicolumn{6}{|c|}{$f_{c}^{\prime}(t)[\mathrm{MPa}]$} \\
\hline & & 0 & 30 & 60 & 90 & 120 & 1 day & 3days & 7days & 28days & 56days & 91days \\
\hline $\mathrm{W} 150$ & 1,550 & 163 & 78.7 & 31 & - & 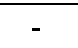 & 25.9 & 27.4 & 29.0 & 31.2 & 32.4 & 33.5 \\
\hline W165 & 1,570 & 216 & 118 & 52 & - & - & 27.2 & 30.0 & 32.0 & 35.0 & 35.2 & 36.4 \\
\hline W180 & 1,589 & 238 & 134 & 82.5 & 31.5 & - & 27.7 & 30.9 & 33.8 & 35.3 & 35.3 & 34.9 \\
\hline W195 & 1,609 & 248 & 144.5 & 105 & 52 & 31 & 28.3 & 33.4 & 35.1 & 37.5 & 38.3 & 39.9 \\
\hline W210 & 1,629 & 255 & 175 & 122 & 108 & 62.4 & 31.7 & 32.8 & 36.1 & 37.8 & 38.0 & 38.6 \\
\hline
\end{tabular}


ACI 209 for cement concrete are also given for comparisons. The compressive strength gain rate of lightweight AA slag concrete was independent of the water content. The strength gain of lightweight AA slag concrete at an early age was highly rapid, indicating that the compressive strength at one day reached as high as above $75 \%$ of the 28 -day compressive strength. As a result, the constant $A_{1}$ for lightweight AA slag concrete was lower than that for OPC concrete and even that for high early strength portland cement concrete cured under steam, as shown in Fig. 7. The high rate of water absorption of the lightweight aggregates and the quick formation of hydrated gels can lead to a higher strength development at an early age. On the other hand, the constant $B_{1}$ for lightweight AA slag concrete was close to 1.0, which was similar to the values for high early strength portland cement concrete cured under steam, regardless of the water content. Overall, the compressive strength development rate of lightweight AA slag concrete cured under room temperature was comparable to that of steam-cured early strength portland cement concrete, as shown in Fig. 6. The lightweight aggregates in a damp state have a beneficial effect on the strength development at a long-term age due to the continuous hydration by the moisture released from the saturated aggregates, which is commonly called as autogenous curing effect $^{11}$. Although, no notable autogenous curing effect was observed in the lightweight AA slag concrete specimens, a stable strength gain was obtained at the long-term age, as shown in Fig. 6 and Table 4.

\subsection{Splitting tensile strength}

In Table 5, the splitting tensile strength, $f_{s p}$, of concrete specimens is given and compared with the empirical equations proposed by EC $2^{15}$ and Slate et al. ${ }^{16}$ for lightweight OPC concrete.
Slate et al. recommended $f_{s p}$ as $0.41 \sqrt{f_{c}^{\prime}}$ based on the empirical regression analysis of lightweight OPC concrete, regardless of $\rho_{c}$. EC 2 expresses $f_{s p}$ as a function of $f_{c}^{\prime}$ and $\rho_{c}$, while no details on $f_{s p}$ are specified in ACI $318-08^{14}$. The normalized splitting tensile strength slightly increased with the increase of the water content, as listed in Table 5. This indicates that the increase of $\rho_{c}$ due to the increased water content and the use of normal-weight fine aggregates can lead to an increase of $f_{s p} / \sqrt{f_{c}{ }^{\prime}}$. The splitting tensile strength of concrete tested is commonly higher than that predicted from the empirical equation recommended by Slate et al., but slightly lower than the predictions obtained from EC 2 equation, regardless of $\rho_{c}$.

\subsection{Modulus of rupture}

Slate et al. recommended the modulus of rupture, $f_{r}$, of drycured lightweight OPC concrete to be optimally fitted as $0.35 \sqrt{f_{c}^{\prime}}$. ACI $318-08$ specifies $f_{r}$ to be $0.465 \sqrt{f_{c}^{\prime}}$ for all-lightweight concrete and $0.527 \sqrt{f_{c}^{\prime}}$ for sand-lightweight concrete. There are no provisions for $f_{r}$ in EC 2. Table 6 provides a comparison between the measured and predicted $f_{r}$ of lightweight AA concrete. The effect of the water content on $f_{r}$ was similar to that observed in $f_{s p}$. The reduced interfacial cracks between aggregates and pastes due to the increased water content can enhance the tensile resistance of concrete. On the other hand, $f_{r}$ of lightweight AA slag concrete is higher than that predicted from the empirical equation recommended by Slate et al., but agrees with the prediction of ACI 318-08, as listed in Table 6.

\subsection{Modulus of elasticity}

The modulus of elasticity, $E_{c}$, of concrete can be commonly expressed as a function of the compressive strength and dry den-

Table 5 Splitting tensile strength.

\begin{tabular}{|c|c|c|c|c|c|c|}
\hline \multirow{2}{*}{ Specimen } & \multirow{2}{*}{$f_{s p} / \sqrt{f_{c}^{\prime}}$} & \multicolumn{3}{|c|}{$f_{s p}[\mathrm{MPa}]$} & \multicolumn{2}{|c|}{$\left(f_{s p}\right)_{\text {Exp. }} /\left(f_{s p}\right)_{\text {Pre }}$} \\
\hline & & Exp. & EC 2* & Slate et al.** & EC 2 & Slate et al. \\
\hline W150 & 0.455 & 2.54 & 2.73 & 2.29 & 0.930 & 1.110 \\
\hline W165 & 0.470 & 2.78 & 2.95 & 2.42 & 0.942 & 1.147 \\
\hline W180 & 0.471 & 2.80 & 2.97 & 2.44 & 0.942 & 1.149 \\
\hline W195 & 0.485 & 2.97 & 3.29 & 2.51 & 0.902 & 1.183 \\
\hline W210 & 0.486 & 2.99 & 3.31 & 2.52 & 0.903 & 1.186 \\
\hline
\end{tabular}

Table 6 Splitting tensile strength.

\begin{tabular}{c|c|c|c|c|c|c}
\hline \multirow{2}{*}{ Specimen } & \multirow{2}{*}{$f_{r} / \sqrt{f_{c}^{\prime}}$} & \multicolumn{3}{|c|}{$f_{r}[\mathrm{MPa}]$} & \multicolumn{2}{c}{$\left(f_{r}\right)_{\text {Exp. }} /\left(f_{\text {sp }}\right)_{\text {Pre. }}$} \\
\cline { 3 - 7 } & & Exp. & ACI 318-08* & Slate et al.** & ACI 318-08 & Slate et al. \\
\hline \hline $\mathrm{W} 150$ & 0.453 & 2.53 & 2.60 & 1.95 & 0.973 & 1.293 \\
\hline $\mathrm{W} 165$ & 0.483 & 2.85 & 2.75 & 2.07 & 1.038 & 1.379 \\
\hline $\mathrm{W} 180$ & 0.506 & 3.01 & 2.76 & 2.08 & 1.089 & 1.447 \\
\hline $\mathrm{W} 195$ & 0.506 & 3.10 & 2.85 & 2.14 & 1.089 & 1.447 \\
\hline $\mathrm{W} 210$ & 0.512 & 3.15 & 2.86 & 2.15 & & 1.464 \\
\hline$*\left(f_{r}\right)_{\text {ACI318 }-08}=0.465 \sqrt{f_{c}^{\prime}}$ for all-lightweight concrete and $0.527 \sqrt{f_{c}^{\prime}}$ for sand-lightweight concrete; \\
$* *\left(f_{r}\right)_{\text {Slate et al. }}=0.35 \sqrt{f_{c}^{\prime}}$.
\end{tabular}


Table 7 Modulus of elasticity.

\begin{tabular}{|c|c|c|c|c|c|c|c|c|}
\hline \multirow{2}{*}{ Specimen } & \multirow{2}{*}{$E_{c} / \sqrt{f_{c}^{\prime}}$} & \multicolumn{4}{|c|}{$E_{c}[\mathrm{MPa}]$} & \multicolumn{3}{|c|}{$\left(E_{c}\right)_{\text {Exp. }} /\left(E_{c}\right)_{\text {Pre }}$} \\
\hline & & Exp. & ACI $318-08^{*}$ & $\mathrm{EC} 2 * *$ & Slate et al.*** & ACI 318-08 & EC 2 & Slate et al. \\
\hline W150 & $2,742.8$ & 15,317 & 14,649 & 16,368 & 13,886 & 1.046 & 0.936 & 1.103 \\
\hline W165 & $2,753.2$ & 16,278 & 15,809 & 16,939 & 14,760 & 1.030 & 0.961 & 1.103 \\
\hline W180 & $2,771.8$ & 16,477 & 16,198 & 16,993 & 15,102 & 1.017 & 0.970 & 1.091 \\
\hline W195 & $2,721.6$ & 16,662 & 16,997 & 19,526 & 15,728 & 0.980 & 0.853 & 1.059 \\
\hline W210 & $2,850.1$ & 17,527 & 17,391 & 19,579 & 16,074 & 1.008 & 0.895 & 1.090 \\
\hline \multicolumn{9}{|c|}{$\begin{array}{l}*\left(E_{c}\right)_{A C I 318-08}=0.043 * \sqrt{f_{c}^{\prime}}\left(\rho_{c}\right)^{1.5} \\
* *\left(E_{c}\right)_{E C 2}=22,000\left(f_{c}^{\prime} / 10\right)^{0.3}\left(\rho_{c} / 2,200\right)^{2}\end{array}$} \\
\hline
\end{tabular}

sity as pointed out by Slate et al., ACI 318-08 and EC 2. The comparison between the measured and predicted $E_{c}$ of concrete tested is given in Table 7. The modulus of elasticity of lightweight AA slag concrete increased with the increase of $\rho_{c}$ which resulted from an increase of the water content. The modulus of elasticity of concrete is significantly affected by the strength and elasticity of the aggregates used, and the quality of cohesion between aggregates and pastes. Therefore, the reduced volume of mixed lightweight aggregates can contribute to an increase of $E_{c}$. The modulus of elasticity of concrete tested agrees with that predicted from the equations recommended by Slate et al. and ACI 318-08. On the other hand, $E_{c}$ predicted from the equation of EC 2 is much higher than the test result and other predictions, because EC 2 overestimates $\rho_{c}$ owing to the use of the upper limit of the density for the relevant class.

\subsection{Shrinkage strain}

The unrestrained shrinkage strain of lightweight AA slag concrete against age is plotted in Fig. 8. The first exposure time of specimens is set to be 0 time in the figure. For comparisons, the predictions obtained from the ACI 209 model based on extensive test results on the normal-weight OPC concrete are also presented on the same figure. No data are saved for specimens A-165, A210 and S-195. Yang et al. ${ }^{21}$ showed that most shrinkage strains in normal-weight slag mortars activated by sodium silicate occur in the first 14 days and then its increasing rate slows down. However,

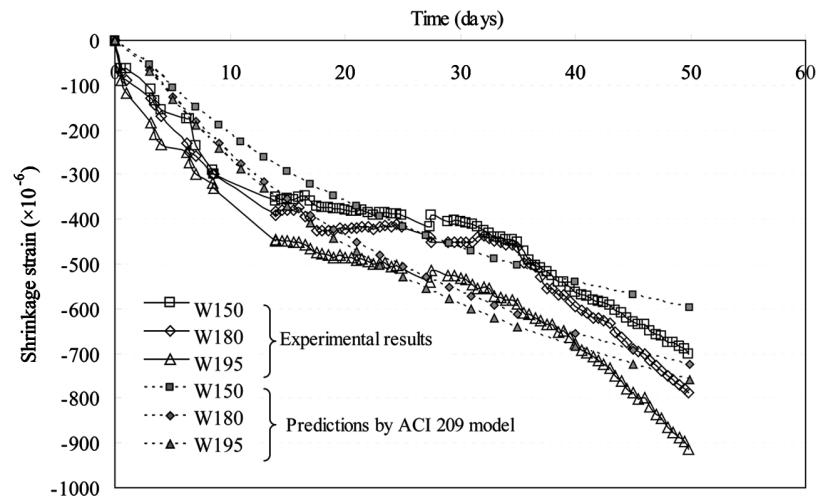

Fig. 8 Shrinkage strain of lightweight AA slag concrete against age. the shrinkage strains of lightweight AA slag concrete linearly increased until the age of 14 days, remained nearly constant until 28 days, and, thereafter, sharply increased again. Overall, the amount of shrinkage strain measured from the lightweight AA slag concrete specimens was larger than that predicted from the empirical model specified in ACI 209 at the early age and after 40 days, as shown in Fig. 8. This may be attributed to a lower stiffness of lightweight aggregates and a gradual release of water absorbed in the lightweight aggregates.

\section{Conclusions}

Based on the tests of 5 all-lightweight alkali-activated (AA) slag concrete specimens and the comparison of the experimental results with the predictions obtained from empirical equations and a database for lightweight ordinary portland cement (OPC) concrete, the following conclusions may be drawn:

1. The slump of concrete tested sharply decreased over the elapsed time, but the increase of the water content alleviated the slump loss of lightweight AA slag concrete.

2. The compressive strength of lightweight AA slag concrete slightly increased with the increase of water content. In addition, the increasing rate of compressive strength against the dry density in lightweight AA slag concrete is similar to that observed in lightweight OPC concrete.

3. The splitting tensile strength, and the moduli of rupture and elasticity of lightweight AA slag concrete were comparatively better than those of lightweight OPC concrete, as a result, they can be conservatively evaluated using the empirical models of Slate et al. or ACI 318-08 proposed for lightweight OPC concrete.

4. The unrestrained shrinkage strain of lightweight AA slag concrete linearly increased until the age of 14 days, remained nearly constant until 28 days, and, thereafter, sharply increased again. Overall, the shrinkage strain measured from the lightweight AA slag concrete specimens was larger than that predicted from the empirical model specified in ACI 209 at an early age and after 40 days, regardless of the water content.

\section{Acknowledgments}

This work was supported by the National Research Foundation of Korea (NRF) grant funded by the Korea government (MEST) 
(No. 2010-0027558) and the Grant of the Korean Ministry of Education, Science and Technology (The Regional Core Research Program/Biohousing Research Institute)

\section{References}

1. Gartner E., "Industrially interesting approaches to lowCO2 cements," Cement and Concrete Research, Vol. 34, No. 9 , 2004, pp. 1489 1498.

2. Mehta P. K., "Reducing the environmental impact of concrete," Concrete International, Vol. 23, No. 10, 2001, pp. 61 66.

3. Yang, K. H., Hwang, H. J., Kim, S. Y., and Song J. K., "Development of a cementless mortar using hwangtoh binder," Building and Environments, Vol. 42, No. 10, 2007, pp. 3717 3725.

4. Pacheco-Torgal, F., Castro-Gomes, J., and Jalali, S., "Alkaliactivated binders: a review. part 2. about materials and binder manufacture," Construction and Building Materials, Vol. 22, No. 7, 2007, pp. 1305 1314.

5. Shi, C., Krivenko, P. V., and Roy, D., Alkali-activated cements and concretes, Taylor and Francis, 2006.

6. Wang, S. D., Pu, X. C., Scrivener, K. L., and Pratt, P. L., "Alkali-activated slag cement and concrete: a review of properties and problems," Advanced Cement Research, Vol. 7, No. 27, 2006, pp. 93 102.

7. Ünal, O., Uygunoðlu, T., and Yildiz, A., "Investigation of properties of low-strength lightweight concrete for thermal insulation," Building and Environments, Vol. 42, No. 2, 2007, pp. 584 590.

8. Neville, A. M., Properties of Concrete, Longman. England, 95 pp.

9. Mouli, M., Khelafi, H., "Performance characteristics of lightweight aggregate concrete containing natural pozzolan," Building and Environments, Vol. 43, No. 1, 2008, pp. 31 36.

10. Kayali, O., "Fly ash lightweight aggregates in high performance concrete," Construction and Building Materials, Vol. 22, No. 12, 2008, pp. 2393 2399.

11. Collins, F. and Sanjayan, J. G., "Strength and shrinkage properties of alkali-activated slag concrete containing porous coarse aggregate," Cement and Concrete Research, Vol. 29, No. 4, 1999, pp. 607 610.

12. Yang, K. H., Song, J. K., and Lee J. S., "Properties of alkaliactivated mortar and concrete using lightweight aggregates," Building and Structures, Vol. 43, No. 2, 2010, pp. 403 416.

13. ACI 209R-92, Prediction of creep, shrinkage, and temperature effects in concrete structures, ACI Manual of Concrete, Practice Part 1, USA, 1994.

14. ACI Committee 318, Building code requirements for structural concrete (ACI 318-08) and Commentary (ACI 318R-08), American Concrete Institute, 2008.

15. European Standard EN 1992-1-1 (Eurocode 2), Design of concrete structures, British Standards Institution, London, UK, 2004.

16. Slate, F. O., Nilson, A. H., and Martinez, S., "Mechanical properties of high-strength lightweight concrete," ACI Journal, Vol. 83, No. 4, 1986, pp. 606 613.

17. Yang, K. H., Modeling of the mechanical properties of structural lightweight concrete based on size effects, Technical report, Kyonggi University, South Korea, 2010.

18. Yang, K. H., Sim, J. I., and Nam, S. H., "Enhancement of reactivity of calcium hydroxide-activated slag mortars by the addition of barium hydroxide," Construction and Building Materials, Vol. 24, No. 3, 2009, pp. 241 251.

19. ACI 211.2-98, Standard practice for selecting proportions for structural lightweight concrete, ACI Committee 211, ACI Standard Practice, USA, 1998.

20. Korean Standards Information Center, Korean industrial standard: testing concrete: KS F 2402-KS F 2414, South Korea, 2006.

21. Yang, K. H., Song, J. K., Ashour, A. F., and Lee, E. T., "Properties of cementless mortar activated by sodium silicate," Construction and Building Materials, Vol. 22, No. 8, 2008, pp. 1981 1989. 